\title{
El poder económico en la Argentina kirchnerista*
}

\author{
Recibido: 05 de octubre de 2017 • Aprobado: 28 de febrero de 2018 \\ DOI: $10.22395 /$ seec.v21n47a8 \\ Lorenzo Cassini** \\ Gustavo García Zanotti ${ }^{* * *}$ \\ Martín Schorr ${ }^{* * * *}$
}

\section{RESUMEN}

El presente trabajo analiza el poder económico de Argentina durante el kirchnerismo (2003-2015). Para ello, se analizaron las empresas de mayor facturación del país con el fin de observar el grado de concentración en la producción y provisión de divisas a través de la balanza comercial. Además, se observaron los cambios en la composición sectorial y de origen del capital. Se concluye que durante las gestiones del kirchnerismo se consolidó el predominio estructural de las grandes firmas, al tiempo que tendió a cristalizarse un nivel elevado de extranjerización de esa elite empresaria, en un escenario signado por un ascenso incipiente de un puñado de capitales nacionales y un cierto retorno del Estado.

\section{PALABRAS CLAVE}

Poder económico; cúpula empresaria; kirchnerismo; Argentina.

\section{CLASIFICACIÓN JEL}

P16, O12, O11, D21.

\section{CONTENIDO}

Introducción; 1. El predominio económico de la cúpula empresaria; 2. Las distintas fracciones del capital que coexisten dentro de la cúpula; 3 . Conclusiones; Bibliografía.

- El presente artículo nuclea diversas líneas de investigación que tienen como denominador común la comprensión del comportamiento y el peso de las empresas más grandes de Argentina durante el periodo de gobiernos kirchneristas. El desarrollo de dichas investigaciones se realizó bajo el ámbito del Conicet.

* Licenciado en economía, Universidad Nacional de Rosario, Rosario, Argentina. Maestrando en desarrollo económico, Universidad General de San Martín, San Martín, Argentina. Doctorando en desarrollo económico, Universidad Nacional de Quilmes, Buenos Aires, Argentina. Becario Doctoral Conicet-Idaes-Unsam. Dirección: Av. Pres. Roque Sáenz Peña 832, Ciudad Autónoma de Buenos Aires, Argentina, C1035AAQ, TE. Teléfono: +549341304-8241. Correo electrónico: lcassini@unsam.edu.ar

.** Licenciado en economía, Universidad Nacional de Rosario, Rosario, Argentina. Doctorando en Desarrollo Económico, Universidad Nacional de Quilmes, Buenos Aires, Argentina. Becario Doctoral CONICET-UNR, Facultad de Ciencias Económicas y Estadística-UNR: Bv. Oroño 1261, Rosario, Argentina, S2000DSM, TE. +549341670-7483, Correo electrónico: gustavo.d.garcia89@gmail.com

..** Licenciado en sociología, Universidad de Buenos Aires, Buenos Aires, Argentina. Magíster en sociología económica, Universidad Nacional General San Martín, San Martín, Argentina. Doctor en Ciencias Sociales, Flacso. Investigador del Idaes-Conicet y docente en la Universidad de Buenos Aires. Dirección: Av. Pres. Roque Sáenz Peña 832, Ciudad Autónoma de Buenos Aires, Argentina, C1035AAQ, TE. Teléfono: +54 9 11 4794-1293. Correo electrónico: schorr.mar@gmail.com 


\title{
ECONOMIC POWER IN KIRCHNERIST ARGENTINA
}

\begin{abstract}
In this paper, the economic power of Argentina during the Kirchnerist period (2003-2015) is analyzed. To do that, the companies with the highest turnover in the country were analyzed in order to observe the degree of concentration in the production and provision of foreign currency through the trade balance. In addition, changes in the sectoral composition and origin of capital were observed. It is concluded that, during the Kirchnerist period, the structural predominance of large firms was consolidated, while a high level of foreignization of that business elite tended to crystallize, in a scenario marked by an incipient rise of a handful of national capitals and a certain return of the State.
\end{abstract}

\section{KEYWORDS}

Economic power; business dome; Kirchnerism; Argentina.

\section{JEL CLASSIFICATION}

P16, O12, O11, D21

\section{O PODER ECONÔMICO NA ARGENTINA KIRCHNERISTA}

\section{RESUMO}

O presente trabalho analisa o poder econômico da Argentina durante o Kirchnerismo (2003-2015).

Para isso, foram analisadas as empresas com maior faturamento no país, a fim de observar o grau de concentração na produção e provisão de divisas através da balança comercial. Além disso, mudanças na composição setorial e na origem do capital foram observadas. Conclui-se que durante as gestões do Kirchnerismo se consolidou o predomínio estrutural das grandes empresas, enquanto um alto nível de estrangeirização da elite empresarial tendia a se cristalizar, em um cenário marcado por uma ascensão incipiente de um punhado de capitais nacionais e um certo retorno do Estado.

\section{PALAVRAS-CHAVE}

Poder econômico; cúpula empresarial; kirchnerismo; Argentina.

\section{CLASSIFICAÇÃO JEL} $\mathrm{P} 16, \mathrm{O} 12, \mathrm{O} 11, \mathrm{D} 21$

\section{CONTEÚDO}

Introdução; 1. Predomínio econômico da cúpula empresarial; 2. Diferentes frações do capital que coexistem dentro da cúpula; 3. Conclusões; Bibliografia. 


\section{INTRODUCCIÓN}

Durante los gobiernos del kirchnerismo en Argentina (2003-2015) tuvieron lugar cambios significativos en la orientación de la intervención estatal frente a lo sucedido bajo el predominio neoliberal. Ello concitó el interés de numerosos sectores académicos y derivó en una proliferación de estudios tendientes a caracterizar el periodo kirchnerista, tanto en su especificidad como en lo que refiere a las continuidades y las rupturas que presentó frente a la década de 1990 en diversas aristas del modo de acumulación prevaleciente en el país: evolución macroeconómica, desempeños sectoriales, perfil de especialización e inserción internacional, posicionamiento externo, mercado de trabajo, distribución del ingreso, etc.

Ahora bien, existe una temática en la cual los estudios que abarcan el conjunto de la etapa son escasos: la trayectoria efectiva del poder económico'. El objetivo del presente trabajo, que se inscribe en dicha línea, es indagar respecto del recorrido de los sectores dominantes durante los gobiernos del kirchnerismo y de los rasgos distintivos de las fracciones del gran capital. Para ello, el universo de análisis se focaliza en la elite o la cúpula empresaria: esto es, las doscientas firmas de mayor facturación anual que se desempeñan en los distintos sectores de la actividad económica².

El tema tratado aquí resulta relevante por varias razones, entre las cuales se destaca el hecho de que muchas de las firmas y los grupos económicos que forman parte de la elite empresaria local son líderes en sectores productivos estratégicos para el país; y, a la vez, tienen una incidencia para nada menor sobre variables clave de la economía como la inversión, las exportaciones, el empleo, la formación de precios y el ingreso y la salida de divisas, entre otras. Además, en el caso de los capitales privados, los propietarios de tales unidades económicas han sido actores poderosos en los planos económico y político, debido a su capacidad para incidir en las decisiones del Estado.

El trabajo se estructura de la siguiente manera. En la primera sección se evalúa la dinámica que asumió la concentración económica global (medida por el peso de la elite empresaria en el conjunto de la producción nacional) durante los gobiernos del kirchnerismo, en aras de discernir los factores que concurren a explicar su trayectoria; y en la segunda, la mirada se dirige a la trayectoria de las fracciones del

\footnotetext{
1 Uno de los aportes fundamentales para el entendimiento del poder económico fue realizado por Azpiazu, Basualdo y Khavisse (1986). Entre las contibuciones existentes para el periodo estudiado se destacan las de Azpiazu, Manzanelli y Schorr (2011), Gaggero y Schorr (2016 y 2017), Gaggero, Schorr y Wainer (2014), García Zanotti (2016), Schorr, Manzanelli y Basualdo (2012), Schorr y Wainer (2016), y Wainer (2013).

2 La cobertura sectorial excluye las actividades financiera y agropecuaria, salvo aquellas compañías que se dedican a la comercialización de granos -que sí están incluidas en el panel-.
} 
capital que conviven al interior de las firmas líderes. Cierran el trabajo unas breves conclusiones.

\section{EL PREDOMINIO ECONÓMICO DE LA CÚPULA EMPRESARIA}

Una primera dimensión de análisis del desenvolvimiento de la elite empresaria durante el ciclo de gobiernos del kirchnerismo es aquella que se focaliza en la evolución del peso de las firmas líderes en el conjunto de la economía argentina. Para ello, en la tabla 1 queda plasmada la evolución de la concentración económica global en el periodo 2001 -2015, es decir, de la incidencia de la cúpula en el valor bruto de producción total ${ }^{3}$.

Tabla 1. Argentina: evolución de la participación de la cúpula empresaria local en el valor bruto de producción total según tramos del ordenamiento, 2001-2015 (en porcentajes)

\begin{tabular}{|c|c|c|c|c|}
\cline { 2 - 5 } \multicolumn{1}{c|}{} & Las 200 & Primeras 50 & Segundas 50 & Segundas 100 \\
\hline 2001 & 21,1 & 13,2 & 4,0 & 3,9 \\
\hline 2002 & 31,0 & 19,7 & 5,8 & 5,5 \\
\hline 2003 & 26,9 & 17,4 & 5,0 & 4,6 \\
\hline 2004 & 26,7 & 16,7 & 5,1 & 4,8 \\
\hline 2005 & 26,5 & 16,8 & 4,9 & 4,8 \\
\hline 2006 & 26,6 & 16,9 & 5,0 & 4,7 \\
\hline 2007 & 26,4 & 16,6 & 4,9 & 4,8 \\
\hline 2008 & 25,9 & 16,4 & 4,8 & 4,7 \\
\hline 2009 & 24,6 & 15,4 & 4,6 & 4,6 \\
\hline 2010 & 23,6 & 14,9 & 4,4 & 4,3 \\
\hline 2011 & 23,8 & 14,7 & 4,6 & 4,5 \\
\hline 2012 & 23,5 & 14,5 & 4,6 & 4,4 \\
\hline 2013 & 24,9 & 15,9 & 4,6 & 4,5 \\
\hline 2014 & 23,2 & 14,9 & 4,1 & 4,2 \\
\hline 2015 & 22,0 & 13,8 & 4,0 & 4,2 \\
\hline
\end{tabular}

Fuente: elaboración propia con información de balances empresarios, revistas Mercado y Prensa Económica e Indec.

3 Para la elaboración del indicador mencionado se tomaron en cuenta los relevamientos del valor bruto de producción del conjunto de la economía que realiza periódicamente el Indec y los ingresos por ventas de las empresas de la cúpula (en ambos casos a precios corrientes). De los desarrollos metodológicos de una investigación previa se toman las ventas de las firmas como un indicador aproximado de su producción (Schorr, 2004). 
Al evaluar el desempeño del indicador al cabo del periodo estudiado resulta posible diferenciar tres momentos:

- Durante el año 2002, que se enmarcó en el contexto de una crisis económica profunda, se dio lugar a una fuerte devaluación del peso argentino frente al dólar, con lo que se alteraron las rentabilidades relativas de la economía a favor de los sectores productores de bienes (en particular, los vinculados con el procesamiento y la exportación de commodities). En este escenario, el indicador se incrementó en forma significativa con un rol destacado de las empresas que integran el núcleo selecto de las primeras 50 de la cúpula;

- A partir de lo anterior, y hasta 2010, se asistió a un declive casi sistemático de la concentración económica global, en línea con una expansión pronunciada de la economía doméstica que tendió a difundirse, con sus más y sus menos, a lo largo de todo el tejido productivo y se asoció, entre otros elementos, a la vigencia de un dólar alto (hasta agosto de 2007); a términos de intercambio favorables para el país; a mejoras importantes en materia distributiva tras la drástica retracción de la participación de los trabajadores en el ingreso que propició la salida devaluatoria de la convertibilidad; y a la existencia de los denominados superávits gemelos (externo y fiscal) $)^{5}$.

- De 2010 en adelante, el indicador ostentó un comportamiento errático en el marco de una economía en franca desaceleración frente a la etapa precedente (incluso con un par de años recesivos): lo anterior estuvo representado por el freno, e incluso en algunos años, el retroceso de las mejoras en la distribución del ingreso, al calor de un elevado ritmo inflacionario y la reaparición de la restricción externa como problemática estructural crítica, unido a la apreciación cambiaria persistente y la irrupción de cambios relevantes en el escenario internacional (caída en la demanda y los precios de los principales productos de exportación de la Argentina, con el consiguiente deterioro en los términos de intercambio) ${ }^{6}$.

A partir de estas constataciones, cabe indagar sobre algunos de los principales factores que, en distintos momentos, pueden haber sentado las bases para un mejor desempeño relativo de las grandes firmas vis-à-vis el conjunto de la economía argentina y, por esa vía, para consolidar estos capitales en un plano estructu-

4 Para un análisis de los rasgos sobresalientes de esta etapa consúltense Cantamutto y Wainer (2013), López (2015) y Piva (2015).

5 Sobre la evolución económica local en estos años, véase, por ejemplo, Centro de Estudios para el Desarrollo Argentino (CENDA) (2010), Kulfas (2016), Manzanelli y Basualdo (2016) y Mercatante (2015).

6 En relación con esta fase, consúltese Damill y Frenkel (2015), Moncaut y Vázquez (2017) y Schorr y Wainer (2015). 
ral. Al respecto, las evidencias disponibles son múltiples y permiten identificar los siguientes elementos:

- El incremento en la tasa bruta de explotación ante la fenomenal caída de los salarios que se verificó en el bienio 2002-2003, así como la considerable apropiación de excedentes que internalizaron muchos oligopolios líderes a partir de la redefinición de los precios relativos y el proceso inflacionario, los cuales signaron el inicio del nuevo esquema económico.

- A favor de su poder de mercado en una diversidad de ámbitos productivos centrales para el funcionamiento de la economía nacional, la posibilidad que suelen tener y aprovechar varias empresas líderes para captar excedentes de modo diferencial, por ejemplo, a través de la fijación oligopólica de precios en escenarios de relativa "reticencia inversora".

- La intensa centralización del capital que tuvo lugar en el marco de la crisis del régimen convertible, así como la integración de muchas firmas de la cúpula a unidades empresarias complejas de tipo holding, que suelen contar con un amplio abanico de opciones en materias tecnoproductiva, comercial y financiera.

- El hecho de que un número importante de las empresas que integran la elite del poder económico local resultaron favorecidas por distintos "ámbitos privilegiados de acumulación" que se generaron o se recrearon en la etapa analizada.

- La inserción de muchas empresas de la cúpula en los sectores productivos más beneficiados por el esquema económico del periodo estudiado (tales son los casos, en distintos momentos, del petróleo y la minería metalífera, varios commodities procedentes del agro y las industrias alimenticia, metálica básica y química, la armaduría automotriz y la electrónica de consumo), así como en la construcción a gran escala y varios rubros terciarios que se favorecieron por el efecto riqueza asociado al crecimiento económico que se verificó durante varios años (telefonía móvil, televisión por cable, medicina privada, hipermercados, venta de electrodomésticos, etc.).

- La importante propensión exportadora de muchas de las grandes compañías a favor del dólar alto hasta agosto de 2007 y la vigencia de mercados externos en expansión por un lapso temporal relativamente extendido (tanto en precios como en lo que alude a las cantidades demandadas) ${ }^{7}$.

$7 \quad$ Sobre los elementos apuntados, consúltense Cassini (2015), González y Manzanelli (2012), Lavarello y Sarabia (2015), Porta, Fernández Bugna y Moldovan (2009), Porta, Santarcángelo y Schteingart (2014), y Schorr (2013). 
En referencia a este último punto, los datos que ofrece la tabla 2 permiten concluir que, hacia el final del ciclo kirchnerista, la elite empresaria dio cuenta de casi el 62 \% de las exportaciones totales de Argentina, luego de alcanzar su punto máximo de participación en 2005 (78,5 \%). Se trata de un elevado nivel de concentración económica de las ventas externas, máxime si se considera que gran parte de esa participación es explicada por las primeras 50. A su vez, todo ello cobra especial relevancia al considerar la centralidad que asumieron los dólares comerciales en el sostenimiento por unos años de la etapa analizada de uno de los pilares del modelo: el superávit comercial. Ese grupo selecto está integrado, en lo sustantivo, por las principales comercializadoras o procesadoras de granos, en particular de soja; las terminales automotrices; algunas firmas líderes de distintos segmentos de la industria alimenticia; varias petroleras; un par de mineras; un puñado de compañías del oligopolio siderúrgico y de la producción químico-petroquímica; y el monopolio del aluminio.

Tabla 2. Argentina: evolución de la participación de la cúpula empresaria local en las exportaciones totales según tramos del ordenamiento*, 2001-2014 (en porcentajes)

\begin{tabular}{|c|c|c|c|c|}
\cline { 2 - 5 } \multicolumn{1}{c|}{} & Las 200 & Primeras 50 & Segundas 50 & Segundas 100 \\
\hline 2001 & 64,2 & 58,3 & 5,8 & 0,1 \\
\hline 2002 & 72,2 & 63,9 & 7,8 & 0,6 \\
\hline 2003 & 76,3 & 69,3 & 6,7 & 0,4 \\
\hline 2004 & 75,3 & 67,5 & 7,4 & 0,4 \\
\hline 2005 & 78,5 & 70,6 & 7,2 & 0,7 \\
\hline 2006 & 74,3 & 66,5 & 7,3 & 0,5 \\
\hline 2007 & 68,2 & 64,1 & 4,1 & 0,0 \\
\hline 2008 & 74,4 & 68,7 & 5,6 & 0,1 \\
\hline 2009 & 70,2 & 65,4 & 4,7 & 0,1 \\
\hline 2010 & 71,5 & 66,4 & 5,0 & 0,1 \\
\hline 2011 & 65,5 & 61,9 & 3,6 & 0,0 \\
\hline 2012 & 66,7 & 61,6 & 5,0 & 0,2 \\
\hline 2013 & 61,4 & 56,8 & 4,5 & 0,1 \\
\hline 2014 & 61,9 & 57,4 & 4,5 & 0,1 \\
\hline
\end{tabular}

• Las empresas del panel se ordenaron en función de sus respectivas exportaciones anuales.

Fuente: elaboración propia con información de balances empresarios, revistas Mercado y Prensa Económica, Indec y Nosis. 
Luego de un periodo inicial de fuerte incremento en el peso de la elite empresaria en rigor de las primeras 50 en las exportaciones agregadas (2001-2005), y de un comportamiento fluctuante desde entonces hasta 2012, en el último trienio estudiado se observa una caída de cinco puntos porcentuales en la incidencia de las grandes firmas en las ventas externas de Argentina (que entre 2012 y 2014 declinaron más del $14 \%$ ), impulsada en lo fundamental por el devenir de las ventas de commodities. En la explicación de este declive exportador, sobre todo en el de las grandes empresas, concurren factores de índole externa (deterioro en los términos de intercambio y menor demanda mundial por efecto de la crisis internacional en general, y la situación económica imperante en Brasil y China en particular) e interna (reducción de los saldos exportables a raíz de la crisis energética y cierta reticencia a liquidar exportaciones por parte de diversos sectores empresarios concentrados ante el rezago cambiario, las expectativas de devaluación y la restricción externa desatada).

La dependencia estructural que se presenta en la economía nacional respecto de los grandes proveedores de divisas por la vía exportadora queda completamente en evidencia al cotejar la evolución entre 2001 y 2014 de la balanza comercial de la Argentina, la de los diferentes estamentos de la elite empresaria y la correspondiente al resto de la economía (tabla 3).

De este recorte surge que, bajo los gobiernos del kirchnerismo, la cúpula registró saldos comerciales superavitarios, mientras que el resto de la economía operó con desbalances pronunciados. Tal grado de heterogeneidad, entre otras cosas, se debe a la reestructuración económico-industrial del periodo 1976-2001 y a ciertos sesgos del planteo económico desplegado en los años bajo estudio (Azpiazu y Schorr, 2010; Castells y Schorr, 2015).

Incluso al interior de la cúpula empresaria se presentan discrepancias, dado que el núcleo duro conformado por las cincuenta firmas de mayor envergadura concentraba en 2014 el 90 \% del superávit del conjunto de la cúpula. Entre otros factores, la vigencia de un dólar alto (hasta agosto de 2007) y la presencia de un escenario mundial favorable (por demanda y precios) indujeron a que esos selectos capitales oligopólicos se hayan fortalecido, en muchos casos, hasta tornarse en plataformas exportadoras sólidas, con una dinámica de acumulación muy poco anclada en el mercado interno $-\mathrm{y}$, por ende, poco alineada con una estrategia de redistribución del ingreso-.

Por la importancia que el kirchnerismo asignó durante varios años a los dólares comerciales (Cantamutto, Schorr y Wainer, 2016), se destaca el control que una cantidad acotada de grandes corporaciones ejerce sobre las divisas de exportación. 
La consolidación estructural de la elite empresaria en la etapa analizada se asoció con cambios relevantes en lo que se refiere a los tipos de empresa existentes en su interior, que ameritan ser analizados y problematizados en la medida en que dotan al kirchnerismo de cierta singularidad histórica. A esa tarea se aboca la próxima sección.

Tabla 3. Argentina: evolución del saldo comercial total y del correspondiente a la cúpula empresaria local y al "resto de la economía", 2001-2014 (en millones de dólares)

\begin{tabular}{|c|c|c|c|c|c|c|}
\hline & Total país & Las 200 & \multirow[t]{2}{*}{ Primeras 50} & \multirow[t]{2}{*}{ Segundas 50} & \multirow{2}{*}{$\begin{array}{c}\text { Segundas } \\
100\end{array}$} & $\begin{array}{c}\text { Resto de la } \\
\text { economía }\end{array}$ \\
\hline & I & II & & & & I-II \\
\hline 2001 & 6.223 & 10.712 & 7.880 & 2.141 & 691 & -4.488 \\
\hline 2002 & 16.661 & 14.915 & 12.024 & 1.678 & 1.213 & 1.746 \\
\hline 2003 & 16.088 & 17.810 & 15.675 & 1.094 & 1.041 & -1.722 \\
\hline 2004 & 12.130 & 16.546 & 14.232 & 1.588 & 726 & -4.416 \\
\hline 2005 & 11.700 & 18.983 & 16.935 & 1.588 & 459 & -7.283 \\
\hline 2006 & 12.393 & 20.754 & 17.317 & 3.372 & 66 & -8.362 \\
\hline 2007 & 11.273 & 22.296 & 21.123 & 3.081 & -1.909 & -11.023 \\
\hline 2008 & 12.556 & 33.779 & 27.714 & 5.019 & 1.047 & -21.223 \\
\hline 2009 & 16.886 & 27.111 & 22.500 & 2.991 & 1.619 & -10.225 \\
\hline 2010 & 11.395 & 31.667 & 29.458 & 811 & 1.398 & -20.273 \\
\hline 2011 & 10.013 & 31.956 & 32.290 & 1.003 & -1.337 & -21.943 \\
\hline 2012 & 12.419 & 32.164 & 27.055 & 4.044 & 1.064 & -19.745 \\
\hline 2013 & 8.003 & 23.200 & 20.562 & 4.199 & -1.561 & -15.197 \\
\hline 2014 & 6.687 & 24.799 & 21.725 & 1.965 & 1.110 & -18.112 \\
\hline
\end{tabular}

Fuente: elaboración propia con información de balances empresarios, revistas Mercado y Prensa Económica, Indec y Nosis.

\section{LAS DISTINTAS FRACCIONES DEL CAPITAL QUE COEXISTEN DENTRO DE LA CÚPULA}

En esta sección se analiza la evolución bajo los gobiernos del kirchnerismo de los diferentes tipos de firma que conforman la cúpula empresaria de Argentina (extranjeras, privadas nacionales, estatales y asociaciones). Para ello, la indagación jerarquiza cuatro dimensiones. La primera remite al desenvolvimiento de las diversas tipologías empresarias a lo largo de las diferentes subetapas que se pueden esta- 
blecer entre 2001 y 2015; la segunda se vincula con las bases sectoriales en torno de las cuales las grandes empresas del medio doméstico tienden a estructurar sus respectivos procesos de acumulación; y la tercera y la cuarta aluden a dos aspectos relevantes: los comportamientos heterogéneos que tuvieron lugar al interior de la principal fracción del gran capital nacional (los grupos económicos) y el retorno del Estado a la propiedad y la gestión de algunas compañías líderes.

\subsection{Dos etapas en la evolución de los diversos segmentos empresarios}

Un análisis entre puntas a partir de los datos de la tabla 4 permite concluir que, bajo el kirchnerismo, el nivel de extranjerización de la elite empresaria doméstica no mostró una retracción significativa. La cantidad de empresas privadas nacionales se mantuvo estable (pasó de 59 a 63), al tiempo que su participación en las ventas globales se incrementó en forma escasa (2,3 puntos porcentuales). Por su parte, las corporaciones extranjeras aumentaron su presencia en lo que atañe a la cantidad de empresas (de 93 a 114), aunque su gravitación en la facturación total declinó algo menos de 4 puntos porcentuales. A su vez, vale destacar el aumento en la presencia estatal (tanto en el número de firmas como en su incidencia en las ventas), pese a lo cual su ponderación resulta insignificante si se la compara con los registros prevalecientes a comienzos de la década de 1990, antes de las privatizaciones (Ortiz y Schorr, 2006); la evolución de las asociaciones, inscrita en una relativa estabilidad en su peso en la facturación global; y un declive pronunciado en la cantidad de empresas que aportan al panel de las líderes de la economía argentina.

Tabla 4. Argentina: distribución de las empresas y las ventas de la cúpula empresaria local según el tipo de accionista predominante de las firmas, 2001, 2007 y 2015 (en valores absolutos y porcentajes)

\begin{tabular}{|l|c|c|c|c|c|c|}
\cline { 2 - 8 } \multicolumn{1}{c|}{} & \multicolumn{4}{c|}{ Cantidad de empresas } & \multicolumn{2}{c|}{ Porcentaje de las ventas de la cúpula } \\
\hline & 2001 & 2007 & 2015 & 2001 & 2007 & 2015 \\
\hline Estatal & 1 & 6 & 3 & 1,6 & 2,1 & 3,2 \\
\hline Privada nacional & 59 & 53 & 63 & 25,3 & 22,8 & 27,6 \\
\hline Privada extranjera & 93 & 116 & 114 & 55,2 & 64,1 & 51,4 \\
\hline Asociación & 47 & 25 & 20 & 17,9 & 11,0 & 17,8 \\
\hline Total & 200 & 200 & 200 & 100,0 & 100,0 & 100,0 \\
\hline
\end{tabular}

Fuente: elaboración propia con información de balances empresarios y revistas Mercado y Prensa Económica.

En esa evolución agregada se reconocen dos subperiodos con lógicas bien disímiles. El primero se extiende entre 2001 y 2007, y abarca los años de mayor cre- 
cimiento y mejoras en las variables socioeconómicas del país. Entre los principales aspectos a remarcar sobresale el retroceso de las empresas privadas nacionales en la cantidad de firmas, así como en su participación en las ventas de la cúpula; este desempeño resulta llamativo si se considera que tuvo lugar en el contexto de gobiernos que se mostraban críticos con el rol del capital extranjero y proclives a la argentinización del gran empresariado. La contracara de estos comportamientos pasa por la fenomenal expansión de las transnacionales: en 2007 había dentro de la cúpula 116 empresas foráneas, que de conjunto concentraban casi las dos terceras partes de la facturación agregada ${ }^{8}$.

En el segundo subperiodo (2007-2015) se revirtió, en parte, el proceso de extranjerización; no obstante, al final de la serie seguía siendo pronunciado en la medida en que bajo la órbita transnacional quedaban involucradas 114 empresas, que aglutinaban más de la mitad de los ingresos por ventas de toda la cúpula. Sin duda, el principal factor explicativo de la tendencia aludida se asocia al hecho de que, entre esos años, Yacimientos Petrolíferos Fiscales (YPF) dejó de estar controlada por la española Repsol y pasa a ser clasificada como asociación', primero a instancias de la adquisición de una cuota-parte accionaria por parte del grupo nacional Petersen; y luego, en 2012, con motivo de la decisión estatal de expropiar la mayoría del capital social de la que constituye la empresa más grande del país ${ }^{10}$. Por otra parte, tuvo lugar un avance de las empresas privadas nacionales, tanto en lo que respecta al número de firmas dentro del ranking como a su ponderación en la facturación agregada (en 2015 eran 63, que congregaban el 27,6 \% de las ventas totales) ${ }^{11}$.

\subsection{La acumulación de capital de las distintas tipologías empresarias}

En esta sección se aborda el tipo de especialización productiva por cada tipología empresaria. Considerado lo anterior, en lo que respecta al capital extranjero, en el ámbito industrial es el actor predominante: se trata de 67 empresas foráneas que en el año 2015 explicaron el 64 \% de las ventas agregadas de la actividad dentro de

8 En buena medida, este fenómeno se explica por: 1), la consolidación de sectores afines a la evolución de la demanda mundial de materias primas en los cuales el capital extranjero concentrado se encontraba inserto, así como a la recuperación de la demanda interna (como el sector automotriz, alimentos y bebidas, etc.); y 2), la venta de ciertas firmas nacionales a manos de capitales externos.

$9 \quad$ La trayectoria de las asociaciones en el periodo analizado se aborda en el apartado 2.4 .

10 El cambio en la estructura de control de YPF es lo que explica, en gran medida, la mayor significación de las asociaciones en las ventas agregadas entre 2007 y 2015. Téngase presente que, en el último de los años señalados, YPF por sí sola dio cuenta de casi el 7 \% de la facturación total de la elite empresaria y del $2 \%$ de todo el valor bruto de producción nacional.

"Este proceso se explica fundamentalmente por la confluencia de la consolidación de ciertas firmas nacionales por sus ventajas comparativas y, como se aborda más adelante, el ascenso de ciertas firmas de capitales nacionales vinculadas a sectores no transables y regulados por el Estado favorecidos con regímenes promocionales específicos. 
la cúpula (tabla 5). La inserción del gran capital transnacional en el espacio fabril se dio en ramas relevantes o estratégicas del entramado productivo, que en muchos casos exhibieron un dinamismo destacado en distintos momentos del ciclo kirchnerista: automotriz, procesamiento de materias primas agropecuarias (incluyendo varios rubros alimenticios), industrias refinadoras, química y petroquímica, electrónica de consumo, algunos nichos de la industria siderúrgica, cemento, celulosa y papel, elaboración de cigarrillos y maquinaria agrícola.

Tabla 5. Argentina: cantidad de empresas extranjeras en la cúpula empresaria local, peso del capital extranjero en las distintas actividades económicas y distribución sectorial de las ventas de las empresas extranjeras, 2015 (en valores absolutos y porcentajes)*

\begin{tabular}{|c|c|c|c|c|}
\hline $\begin{array}{l}\text { Actividad } \\
\text { principal }\end{array}$ & Empresas & $\begin{array}{c}\text { Peso en las } \\
\text { ventas de la } \\
\text { actividad }\end{array}$ & $\begin{array}{c}\text { Distribución } \\
\text { sectorial de las } \\
\text { ventas }\end{array}$ & Principales empresas* \\
\hline Industria & 67 & 64,0 & 58,2 & $\begin{array}{l}\text { Shell, Volkswagen, Cargill, Toyota, Ford, } \\
\text { Louis Dreyfus, Bunge, Cervecería Quil- } \\
\text { mes, Unilever, Peugeot-Citroen, Renault, } \\
\text { General Motors, Fiat Auto, PBB Polisur, } \\
\text { Acindar, Mercedes Benz, Nestlé, Dano- } \\
\text { ne, Oleaginosa Moreno, Embotelladora } \\
\text { del Atlántico, Coca Cola, Kraft Foods, } \\
\text { Massalin Particulares, Procter \& Gam- } \\
\text { ble, Loma Negra }\end{array}$ \\
\hline Servicios & 17 & 38,1 & 15,2 & $\begin{array}{l}\text { Claro, Movistar, Swiss Medical, } \\
\text { Telefónica de Argentina, Direct TV, } \\
\text { DLS, Isolux, Lan Airlines, IBM, Prosegur, } \\
\text { Omint, Halliburton, Securitas, Baker } \\
\text { Hughes, Nextel, Accenture, Ultrapetrol }\end{array}$ \\
\hline Comercio & 18 & 59,9 & 19,0 & $\begin{array}{l}\text { Carrefour, Jumbo Retail, Walmart, Nide- } \\
\text { ra, Supermercado Día, Cencosud, Noble, } \\
\text { Makro, ADM, Falabella, Casino, Alfred } \\
\text { Toepfer, CHS, Arcos Dorados, Amaggi, } \\
\text { Sodimac, Interbaires }\end{array}$ \\
\hline Petróleo & 7 & 18,5 & 5,2 & $\begin{array}{l}\text { Petrobras, San Antonio, Sinopec, Win- } \\
\text { tershall, Total Austral, Chevron San Jor- } \\
\text { ge, Wild }\end{array}$ \\
\hline Minería & 4 & 100,0 & 2,1 & $\begin{array}{l}\text { Oroplata, Minera Argentina Gold, Minera } \\
\text { Alumbrera, Cerro Vanguardia }\end{array}$ \\
\hline Construcción & 1 & 16,1 & 0,3 & Tecna \\
\hline Total & 114 & 51,4 & 100,0 & 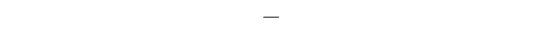 \\
\hline
\end{tabular}

• Las empresas se ordenan de modo decreciente en función del monto de sus ventas en 2015.

Fuente: elaboración propia con información de balances empresarios y revistas Mercado y Prensa Económica. 
En orden de importancia en la industria, el segundo lugar lo ocupan las empresas privadas nacionales (la participación de las asociaciones en la actividad es marginal). En este caso, en 2015 aportaron al panel 28 empresas que pertenecen en su mayoría a grupos económicos locales y dieron cuenta de casi el 31 \% de la facturación sectorial. En esta fracción del gran capital, la inserción fabril se vincula con distintos rubros agroindustriales y, en menor medida, con la fabricación de algunos insumos intermedios de uso difundido (por ejemplo, acero y aluminio), medicamentos y productos electrónicos (tabla 6) ${ }^{12}$.

Tabla 6. Argentina: cantidad de empresas privadas nacionales en la cúpula empresaria local, peso del capital privado nacional en las distintas actividades económicas y distribución sectorial de ventas de las empresas privadas nacionales, 2015 (en valores absolutos y porcentajes)

\begin{tabular}{|c|c|c|c|c|}
\hline $\begin{array}{l}\text { Actividad } \\
\text { principal }\end{array}$ & Empresas & $\begin{array}{l}\text { Peso en las } \\
\text { ventas de la } \\
\text { actividad }\end{array}$ & $\begin{array}{l}\text { Distribución } \\
\text { sectorial de las } \\
\text { ventas }\end{array}$ & Principales empresas* \\
\hline Industria & 28 & 30,8 & 52,2 & $\begin{array}{l}\text { Aceitera General Deheza, Asociación de } \\
\text { Coops. Argentinas, Arcor, Vicentín, Moli- } \\
\text { nos Río de la Plata, Siderar, Newsan, Mas- } \\
\text { tellone, Sancor, Siderca, Aluar, Mirgor, } \\
\text { latec, Electronic System, BGH, Ledesma, } \\
\text { Molinos Cañuelas, Roemmers, Agea, Siat }\end{array}$ \\
\hline Servicios & 18 & 31,5 & 23,4 & $\begin{array}{l}\text { Osde, Galeno, Clisa, Pampa Energía, } \\
\text { Unión Personal, Rafael Albanesi, Soc. } \\
\text { Italiana de Benef., Casino Buenos Aires, } \\
\text { Pecom Servicios de Energía }\end{array}$ \\
\hline Comercio & 10 & 33,4 & 19,7 & $\begin{array}{l}\text { Coto, Importadora y Exportadora Pata- } \\
\text { gonia, Garbarino, Droguería del Sud, Far- } \\
\text { macity, Frávega, Megatone, Maycar, Agric. } \\
\text { Federados Arg., Carsa }\end{array}$ \\
\hline Petróleo & 2 & 3,1 & 1,6 & Pluspetrol, Tecpetrol \\
\hline Minería & 0 & 0,0 & 0,0 & - \\
\hline Construcción & 5 & 83,9 & 3,1 & $\begin{array}{l}\text { Techint, lecsa, Benito Roggio, José Car- } \\
\text { tellone, Electroingeniería }\end{array}$ \\
\hline Total & 63 & 27,6 & 100,0 & - \\
\hline
\end{tabular}

- Las empresas se ordenan de modo decreciente en función del monto de sus ventas en 2015. Las firmas resaltadas en itálicas pertenecen a grupos económicos.

Fuente: elaboración propia con información de balances empresarios y revistas Mercado y Prensa Económica.

12 La mayoría de las compañías locales promovidas por el régimen fueguino funcionan bajo licencias extranjeras (algunas tienen, además, líneas de productos propias) y pagan regalías por la fabricación. Las grandes marcas internacionales suelen proveer la tecnología y los insumos, y controlan que los procesos se realicen de acuerdo con sus protocolos. 
En el campo de los servicios, se concluye que las tres tipologías tienen una participación similar en la facturación agregada de la actividad (en torno de un tercio cada una). La inserción del capital extranjero se ordena, en buena medida, con base en firmas abocadas a la prestación del servicio telefónico celular y fijo, la medicina privada y grandes proveedoras de la industria petrolera. En las privadas nacionales hay varias del rubro de la medicina prepagada, pero también de la recolección y el tratamiento de residuos, diferentes segmentos energéticos, juegos de azar y negocios inmobiliarios. En tanto, en las asociaciones casi todas son prestatarias de servicios públicos; y una de televisión por cable y actividades conexas (tabla 7).

Tabla 7. Argentina: cantidad de asociaciones en la cúpula empresaria local, peso de las asociaciones en las distintas actividades económicas y distribución sectorial de las ventas de las asociaciones, 2015 (en valores absolutos y porcentajes)

\begin{tabular}{|c|c|c|c|c|}
\hline $\begin{array}{l}\text { Actividad } \\
\text { principal }\end{array}$ & Empresas & $\begin{array}{c}\text { Peso en las } \\
\text { ventas de la } \\
\text { actividad }\end{array}$ & $\begin{array}{c}\text { Distribución } \\
\text { sectorial de las } \\
\text { ventas }\end{array}$ & Principales empresas* \\
\hline Industria & 5 & 5,2 & 13,5 & $\begin{array}{l}\text { Axion Energy, Bagley, Refinor, Profer- } \\
\text { til, Mega }\end{array}$ \\
\hline Servicios & 8 & 26,7 & 30,6 & $\begin{array}{l}\text { Telecom Argentina, Telecom Personal, } \\
\text { Cablevisión, Aeropuertos Argentina } \\
\text { 2000, Gas Argentino, Transportadora } \\
\text { de Gas del Sur, Edesur, Edenor }\end{array}$ \\
\hline Comercio & 3 & 6,8 & 6,1 & $\begin{array}{l}\text { Mercado Libre, Droguería Suizo Argenti- } \\
\text { na, Droguería Monroe Americana }\end{array}$ \\
\hline Petróleo & 4 & 61,6 & 49,7 & $\begin{array}{l}\text { YPF, Pan American Energy, Evangelis- } \\
\text { ta, Comp. Hidrocarburos no Conven- } \\
\text { cionales }\end{array}$ \\
\hline Minería & 0 & 0,0 & 0,0 & - \\
\hline Construcción & 0 & 0,0 & 0,0 & - \\
\hline Total & 20 & 17,8 & 100,0 & - \\
\hline
\end{tabular}

- Las empresas se ordenan de modo decreciente en función del monto de sus ventas en 2015.

Fuente: elaboración propia con información de balances empresarios y revistas Mercado y Prensa Económica.

El comercio es otra de las ramas con un marcado predominio extranjero. En 2015 las empresas foráneas explicaron cerca del 60 \% de la facturación sectorial de la cúpula empresaria, a instancias de grandes cadenas de supermercados e importantes traders de granos. Las compañías privadas nacionales dieron cuenta de algo más del $33 \%$ de las ventas de la actividad, sobre todo a partir de algunos hipermercados y varias firmas de venta de electrodomésticos. 
En la producción hidrocarburífera, el liderazgo es ejercido por las asociaciones: siempre en 2015, alrededor del $62 \%$ de las ventas sectoriales fueron generadas por cuatro empresas de esta tipología; en este sentido, la influencia de YPF y, en menor grado, de Pan American Energy, es determinante. Por su parte, las compañías transnacionales generaron casi el 20 \% de la facturación de la actividad (la gravitación de las privadas nacionales es irrelevante).

Por otro lado cabe consignar que, en el caso de la minería, la totalidad de las ventas procede de cuatro megaemprendimientos controlados por transnacionales; mientras que en la construcción, la mayor ponderación le corresponde a cinco empresas privadas nacionales, todas las cuales forman parte de grupos económicos.

En lo que respecta al perfil sectorial de cada una de las tipologías, los datos aportados en la tabla 5 permiten afirmar que, en 2015, el grueso de la facturación del capital extranjero que forma parte de la cúpula $(58,2 \%)$ provino de actividades industriales, muchas de las cuales resultan "críticas" dada su incidencia en materia intra e interindustrial, o que en distintos momentos de los gobiernos kirchneristas se expandieron apuntaladas por diversos factores internos o externos. El segundo rubro relevante en la operatoria del gran capital foráneo es el comercial (19 \% de las ventas de la tipología); el tercero, la prestación de servicios (15,2 \%); y el cuarto, la producción petrolera (5,2 \%).

En lo que atañe a la acumulación del capital de las empresas privadas nacionales, cabe resaltar la importancia que asume la industria: en 2015, esta actividad dio cuenta del 52,2 \% de las ventas totales de la tipología; como se dijo, estas provienen en su mayoría en firmas que se integran en conglomerados empresarios, que usufructúan ventajas comparativas estáticas o institucionales de privilegio ${ }^{13}$ (tabla 6). Por su injerencia relativa en la facturación (23,4\%), el segundo lugar lo ocupa la prestación de servicios, seguido de la actividad comercial (19,7 \%). Por otro lado, es interesante reparar en que el gran capital nacional es mayoritario en la construcción; sin embargo, este rubro explica apenas el 3,1 \% de sus ventas.

Las evidencias de la tabla 7 permiten corroborar que, en las asociaciones, alrededor de la mitad de la facturación total fue generada por empresas petroleras (con el señalado liderazgo de YPF y Pan American Energy, que en 2015 ocuparon los puestos 1 y 12 del ranking); algo menos de un tercio, por prestatarias de servicios (básicamente por compañías emergentes del proceso privatizador de la década de 1990); y cerca de la séptima parte, por firmas industriales (refinadoras y productoras de alimentos, insumos petroquímicos y abonos y fertilizantes).

13 Para una cabal comprensión de los ámbitos privilegiados de acumulación, véase Castellani (2009). 


\subsection{Los comportamientos heterogéneos de los grupos económicos nacionales ${ }^{14}$}

Bajo los gobiernos kirchneristas se verificaron modificaciones relevantes dentro de los grupos económicos nacionales, al calor de estrategias y trayectorias divergentes que ameritan ser estudiadas y caracterizadas por cuanto expresan la existencia de ciertos procesos específicos o novedosos de esta etapa histórica.

A los efectos de establecer un mapa de perdedores y ganadores al interior de esta fracción del poder económico o, en otros términos, de captar los desempeños heterogéneos que tuvieron lugar, se procedió a clasificar a las empresas de la cúpula que pertenecen a grupos locales en cinco tipologías, según sus respectivos senderos evolutivos entre 2001 y 2015. Las dos primeras expresan a los holdings perdedores, sea porque las firmas de su propiedad salieron por algún motivo del panel de las doscientas líderes (tipología I), o porque redujeron su participación en los montos globales facturados (II). Las otras tres categorías congregan a los grupos ganadores: se trata de organizaciones que lograron mantener su ponderación en las ventas totales (III), las que la aumentaron (IV) y las que lograron ingresar a la cúpula (V). Los resultados de esta indagación analítica se vuelcan en la tabla 8.

En cuanto a los grupos perdedores, cabe consignar que en la tipología I quedan involucrados 14 conglomerados cuyas empresas dejaron de integrar la elite empresaria local entre 2001 y 2015 (en el primero de los años mencionados su participación en las ventas agregadas de la cúpula fue del 3,1 \%). En su mayor parte, se trata de organizaciones que fueron vendidas al capital extranjero en los primeros años del periodo analizado, debido a problemas financieros que se habían agravado en el tramo final de la convertibilidad o que, por diferentes razones, tuvieron que afrontar la quiebra o un proceso de desmembramiento de la unidad económica principal. Entre los grupos más relevantes se destacan Fortabat, Soldati, Backchellián, Acevedo, Garovaglio y Zorraquín, Macri y Pescarmona.

Por su parte, la tipología II congrega a los grupos económicos que mantuvieron su presencia en la cúpula entre 2001 y 2015 pero reduciendo su participación. Aquí quedan involucrados 9 conglomerados que en el último de los años estudiados controlaban 14 empresas del panel de las doscientas líderes, cuyas ventas representaban el 6,9 \% de la facturación global (una ponderación que resulta casi 5 puntos porcentuales más baja que en 2001). Se trata de organizaciones importantes (en conjunto explican cerca de la tercera parte de las ventas totales de los grupos locales en 2015) con una historia más o menos prolongada dentro del poder económico doméstico, bastante heterogéneas en cuanto a su perfil sectorial. En

\footnotetext{
14 Este apartado recupera, en parte, los desarrollos de Gaggero y Schorr (2017).
} 
esta categoría sobresale la presencia de tres grupos relevantes: Techint, Eurnekián y Pérez Companc.

Tabla 8. Argentina: evolución de los grupos económicos nacionales dentro de la cúpula empresaria según su situación en 2001 y 2015 (en valores absolutos y porcentajes)

\begin{tabular}{|c|c|c|c|c|c|c|}
\hline & $\begin{array}{c}\text { Grupos que dejaron } \\
\text { de integrar la cúpula } \\
\text { entre } 2001 \text { y } 2015 \\
\text { (I) }\end{array}$ & $\begin{array}{l}\text { Grupos que } \\
\text { redujeron su } \\
\text { participación } \\
\text { entre } 2001 \text { y } \\
2015 \\
\text { (II) }\end{array}$ & $\begin{array}{c}\text { Grupos que } \\
\text { no variaron su } \\
\text { participación entre } \\
2001 \text { y 2015* } \\
\text { (III) }\end{array}$ & \begin{tabular}{|} 
Grupos que \\
incrementaron \\
su participación \\
entre 2001 y \\
2015 \\
(IV)
\end{tabular} & $\begin{array}{c}\text { Grupos que pasaron a } \\
\text { integrar la cúpula entre } \\
2001 \text { y } 2015 \\
\text { (V) }\end{array}$ & Total \\
\hline & \multicolumn{6}{|c|}{ Cantidad de grupos } \\
\hline 2001 & 14 & 9 & 4 & 12 & - & 39 \\
\hline 2015 & - & 9 & 4 & 12 & 12 & 37 \\
\hline \multicolumn{7}{|c|}{ Cantidad de empresas } \\
\hline 2001 & 15 & 18 & 5 & 16 & - & 54 \\
\hline 2015 & - & 14 & 5 & 17 & 16 & 52 \\
\hline \multicolumn{7}{|c|}{ Participación en las ventas de la cúpula } \\
\hline 2001 & 3,1 & 11,7 & 1,7 & 7,7 & - & 24,2 \\
\hline 2015 & - & 6,9 & 1,8 & 11,1 & 4,1 & 23,8 \\
\hline \multicolumn{7}{|c|}{ Participación en las ventas de los grupos nacionales } \\
\hline 2001 & 16,3 & 46,2 & 6,8 & 30,7 & - & 100,0 \\
\hline 2015 & - & 29,0 & 7,3 & 46,6 & 17,1 & 100,0 \\
\hline \multicolumn{7}{|c|}{ Nombres de los grupos } \\
\hline & $\begin{array}{l}\text { Macri, Acevedo, } \\
\text { Fortabat, Rohm, } \\
\text { Cirigliano, } \\
\text { Peñaflor, Sadesa } \\
\text { (curtiembre), } \\
\text { Bakchellián, } \\
\text { Gualtieri, } \\
\text { Williner, } \\
\text { Garovaglio } \\
\text { y Zorraquín, } \\
\text { Agrocom, } \\
\text { Pescarmona, } \\
\text { Soldati }\end{array}$ & $\begin{array}{l}\text { Techint, } \\
\text { Pérez } \\
\text { Companc, } \\
\text { Sancor, } \\
\text { Machiavello } \\
\text { (Temis), } \\
\text { Roemmers, } \\
\text { Coto, } \\
\text { Bemberg, } \\
\text { Barracas, } \\
\text { Eurnekián }\end{array}$ & $\begin{array}{l}\text { Mastellone, } \\
\text { Madanes, } \\
\text { Ledesma, La } \\
\text { Nación }\end{array}$ & $\begin{array}{l}\text { Urquía, } \\
\text { Roggio, } \\
\text { Clarín, Arcor, } \\
\text { Vicentín, } \\
\text { Osde, Braun } \\
\text { Menéndez, } \\
\text { BGH, Navilli, } \\
\text { Garbarino, } \\
\text { Frávega, } \\
\text { Pluspetrol }\end{array}$ & $\begin{array}{l}\text { Cartellone, Pampa } \\
\text { Energía, Indalo } \\
\text { (Cristóbal López), } \\
\text { ODS (Calcaterra), } \\
\text { IRSA, Caputo, } \\
\text { PCR, Newsan } \\
\text { (Cherñajovsky), } \\
\text { Gador, Sadesa } \\
\text { (energía), } \\
\text { Electroingeniería, } \\
\text { Insud (Sigman) }\end{array}$ & \\
\hline
\end{tabular}

- Se trata de grupos cuya variación en la participación en las ventas entre 2001 y 2015 fue inferior al 10 \%.

Fuente: elaboración propia con información de balances empresarios y revistas Mercado y Prensa Económica. 
Ahora bien, cabe aclarar que ni en el caso de Techint ni en el de Eurnekián se podría afirmar que se trata de grupos perdedores bajo los gobiernos del kirchnerismo: si bien la participación de las firmas de su propiedad que operan en el país tendió a reducirse en la cúpula, estos capitales llevaron adelante una expansión en el extranjero que los dotó de una estructura similar en varios aspectos a la de muchas empresas transnacionales.

En el caso de Pérez Companc vale apuntar que su menor peso relativo dentro de la elite empresaria doméstica se relaciona con la venta de su rama energética a Petrobras. Esta operación fue parte de una reconversión estratégica que llevó a Pérez Companc a especializarse en la producción de alimentos.

Yendo a los grupos económicos ganadores, la información que ofrece la tabla 8 permite concluir que 4 conglomerados no variaron su gravitación dentro del poder económico local entre 2001 y 2015 (tipología III). Tal es el caso de uno de los líderes de la industria láctea (Mastellone); el propietario del monopolio fabricante de aluminio (Madanes); uno de los principales holding multimedia del país (La Nación); y un conglomerado con cierta diversificación de sus actividades (Ledesma, con intereses en rubros como la producción de azúcar, papel y derivados, frutas y jugos concentrados, carne, cereales, alcohol y bioetanol, entre otros). En conjunto, hacia el final del periodo estudiado, estos actores dieron cuenta de casi el $2 \%$ de las ventas totales de la cúpula y más del 7 \% de la facturación de los grupos económicos que la integran.

Por su parte, dentro de la tipología IV quedan involucrados 12 conglomerados que aumentaron de modo destacado su participación dentro de la elite empresaria. A raíz de esto, en 2015 controlaban un total de 17 firmas del panel, que daban cuenta del $11,1 \%$ de la facturación global de la cúpula y casi la mitad de las ventas totales de los grupos económicos nacionales que forman parte de ella. En esta categoría se destacan organizaciones agroindustriales con fuerte inserción exportadora, anclada principalmente en el sector de aceites y harinas (Urquía, Vicentín y Navilli). Bajo las administraciones kirchneristas, estos capitales resultaron favorecidos por la concurrencia de diversos factores, entre los que sobresalen la vigencia de condiciones excepcionales en el mercado mundial durante varios años; la consolidación de un perfil de especialización e inserción internacional del país muy volcado al procesamiento de materias primas; la existencia durante un cierto lapso temporal de un elevado tipo de cambio real; y la dinámica de los precios relativos en el plano doméstico.

Arcor es otro ejemplo de comportamiento expansivo durante el kirchnerismo. El año 2003 marcó el inicio de una recuperación acelerada que repercutió en for- 
ma positiva en sus ventas internas y externas, lo mismo que en sus márgenes de rentabilidad. En esa expansión resultó fundamental la relación que el grupo había establecido con el mercado mundial bajo la convertibilidad, tanto en lo referido a exportaciones como a inversiones en otros países. En el periodo analizado, el holding, uno de los principales fabricantes de golosinas a escala global, afianzó su inserción internacional mediante la incorporación de nuevas plantas industriales, oficinas comerciales y centros de distribución, y la celebración de alianzas estratégicas con jugadores mundiales como Nestlé, Coca Cola, Bimbo y Brach's, entre otros. A su vez, fortaleció su presencia en la producción de galletitas, alimentos enlatados y helados.

Asimismo, dentro de la tipología IV aparece un conjunto de grupos económicos centrados en el ensamblado y la comercialización de productos electrónicos de consumo (Garbarino, Frávega y BGH), cuya expansión en el periodo se desprende del fuerte crecimiento que experimentaron estas actividades al calor del estímulo que recibió, por diferentes vías, el régimen promocional vigente en Tierra del Fuego. También forman parte de ella un holding líder del mercado ampliado de las telecomunicaciones (Clarín); otro con presencia destacada en el segmento del comercio minorista (Braun Menéndez); y dos ligados a sectores no transables como la construcción y la recolección de residuos (Roggio) y la prestación privada de servicios médicos (OSDE).

Por último, la tipología $V$ engloba a los grupos económicos nacionales que por distintos motivos no tenían empresas dentro de la cúpula en 2001 y sí las tuvieron en 2015. Se trata de 12 conglomerados que en el último de los años controlaban 16 compañías del ranking y congregaban algo más del $4 \%$ de las ventas agregadas de las doscientas firmas líderes, y el 17,1 \% de la facturación total de los conglomerados locales. En la generalidad de los casos, se trata de actores que con anterioridad a la etapa bajo análisis, habían tenido un lugar marginal o inexistente en el seno del poder económico doméstico. Si bien la mayoría de estos holdings nuevos son de un tamaño bastante menor que muchos de los históricos, no puede obviarse que experimentaron un crecimiento considerable en los últimos años: el rol del Estado y las relaciones fluidas con el sistema político jugaron un papel central en el ascenso de este nuevo poder económico durante los gobiernos kirchneristas (Gaggero, Schorr y Wainer, 2014).

En este punto, sobresale en primer lugar un conjunto de grupos económicos cuya acumulación tiene como epicentro el sector de la construcción y los bienes raíces: Cartellone, ODS, IRSA, Caputo y Electroingeniería. En la mayoría de los casos, la obra pública resultó clave en su expansión reciente y la cercanía al poder 
político fue un rasgo compartido por la mayoría de sus propietarios. En segundo lugar se destacan los conglomerados que en la etapa estudiada ganaron terreno en el ámbito de los servicios públicos, agrupados en el campo de la energía eléctrica: Pampa Energía y Sadesa. Dentro de esta categoría cabe destacar, además, los casos de Indalo, Newsan e Insud. El primero es un conglomerado de firmas que la última década del siglo xx era una organización mediana anclada, en lo sustantivo, en los juegos de azar en el sur del país; en el kirchnerismo se convirtió en un actor central en el negocio del juego a escala nacional, se posicionó de manera estratégica en el sector petrolero y se diversificó hacia otras actividades (agro, construcción y medios de comunicación). Por su parte, el grupo Newsan es titular de un puñado de empresas que resultaron favorecidas por la promoción a la electrónica de consumo que se instrumentó, mientras que Insud basó su expansión en la producción de medicamentos, al tiempo que se diversificó hacia los agronegocios y diversas actividades culturales y turísticas.

\subsection{El incipiente "retorno" del Estado}

Al analizar la evolución de los diferentes tipos de empresa durante el kirchnerismo (tabla 4) se establece un cierto avance de las firmas controladas por el Estado nacional, cuya participación en 2015 en las ventas totales de la cúpula apenas superó el $3 \%^{15}$. Sin embargo, en la etapa analizada, y en especial en el segundo de los subperiodos delimitados (2007-2015), tuvo lugar una creciente influencia del sector público a través de las asociaciones, es decir, de grandes firmas cuya propiedad es compartida por distintos tipos de capitales.

De la información suministrada en la tabla 9 se desprende que, entre 2001 y 2007, alrededor del 80 \% de las ventas totales de las asociaciones correspondía a empresas en cuya estructura accionaria era mayoritario el capital extranjero. A partir de entonces el cambio más notable pasa por la irrupción estatal: en 2015, el 45,8 \% de la facturación de las asociaciones fue generado por 7 firmas cuyo socio predominante es el Estado argentino. Ello es resultado directo de la decisión tomada en mayo de 2012 de expropiar el 51 \% del capital accionario que el holding español Repsol poseía en YPF y sus empresas asociadas.

La renovada presencia estatal en la propiedad y la gestión de grandes empresas también se asocia con la concreción de una serie de estatizaciones en distintos momentos de los gobiernos kirchneristas (tabla 10). Estas no formaron parte de un plan diseñado para incrementar de forma estratégica la presencia del sector

15 En cuanto al avance de las empresas de control estatal, vale destacar que la mayoría se rige bajo principios del derecho privado. 
público en la economía; más bien fueron respuestas tácticas ensayadas en determinadas coyunturas críticas (Gaggero, Schorr y Wainer, 2014).

Tabla 9. Argentina: cantidad de asociaciones dentro de la cúpula empresaria, distribución de las ventas y peso de las asociaciones en las ventas de la cúpula según el accionista mayoritario, 2001, 2007 y 2015 (en valores absolutos y porcentajes)

\begin{tabular}{|c|c|c|c|c|c|c|c|c|c|c|}
\hline & & $\begin{array}{l}\text { antidad } \\
\text { ociacior }\end{array}$ & & Distri & $\begin{array}{l}\text { ibución } \\
\text { ventas }\end{array}$ & de las & $\begin{array}{l}\text { Partici } \\
\text { ventas }\end{array}$ & $\begin{array}{l}\text { ipación } \\
\text { de la }\end{array}$ & $\begin{array}{l}\text { en las } \\
\text { cúpula }\end{array}$ & Principales empresas (2015)* \\
\hline & 2001 & 2007 & 2015 & 2001 & 2007 & 2015 & 2001 & 2007 & 2015 & \\
\hline $\begin{array}{l}\text { Predominio } \\
\text { nacional-estatal }\end{array}$ & 0 & 0 & 7 & 0,0 & 0,0 & 45,8 & 0,0 & 0,0 & 8,2 & $\begin{array}{l}\text { YPF, Evangelista, Gas } \\
\text { Argentino, CHNC, Re- } \\
\text { finería del Norte, Pro- } \\
\text { fertil, Mega** }\end{array}$ \\
\hline $\begin{array}{l}\text { Predominio } \\
\text { extranjero }\end{array}$ & 33 & 18 & 9 & 79,3 & 81,5 & 44,1 & 14,2 & 9,0 & 7,9 & $\begin{array}{l}\text { Telecom, Axion Ener- } \\
\text { gy, Pan American } \\
\text { Energy, Telecom Per- } \\
\text { sonal, Mercado Libre, } \\
\text { Bagley, Monroe Ame- } \\
\text { ricana, Transporta- } \\
\text { dora de Gas del Sur, } \\
\text { Edesur }\end{array}$ \\
\hline $\begin{array}{l}\text { Predominio } \\
\text { nacional-privado }\end{array}$ & 14 & 7 & 4 & 20,7 & 18,5 & 10,1 & 3,7 & 2,0 & 1,8 & $\begin{array}{l}\text { Cablevisión, Drogue- } \\
\text { ría Suizo-Argentina, } \\
\text { Aeropuertos Argenti- } \\
\text { na 2000, Edenor }\end{array}$ \\
\hline Total & 47 & 25 & 20 & 100,0 & 100,0 & 100,0 & 17,9 & 11,0 & 17,8 & - \\
\hline
\end{tabular}

- Las empresas se ordenan de modo decreciente en función del monto de sus ventas en 2015.

.* Todas las firmas integran el conglomerado empresario en torno a YPF.

Fuente: elaboración propia con información de los balances empresarios y revistas Mercado y Prensa Económica.

En los primeros años de la gestión del kirchnerismo acaecieron intervenciones por medio de las cuales se buscó rescatar a empresas que se encontraban en una difícil situación financiera y operativa (Correo Argentino, Aerolíneas Argentinas, Aguas Argentinas). Las estatizaciones más importantes de los años siguientes se debieron a razones distintas, vinculadas a la emergencia de serios problemas energéticos (YPF y Metrogas) y a la necesidad de obtener fuentes de financiamiento alternativas ante la reducción del superávit fiscal y la imposibilidad de fijar retenciones móviles a las exportaciones de algunos cereales, tras la disputa del gobierno con las patronales del sector agropecuario (sistema previsional). 
Tabla 10. Argentina: principales empresas privadas que pasaron a estar bajo control del Estado en el periodo 2003-2015

\begin{tabular}{|l|c|l|}
\hline \multicolumn{1}{|c|}{ Empresa } & $\begin{array}{c}\text { Año de la } \\
\text { operación }\end{array}$ & \multicolumn{1}{|c|}{ Propietario anterior } \\
\hline Correo Argentino & 2003 & Grupo Macri \\
\hline Enarsa & 2004 & Creación de empresa \\
\hline Aguas Argentinas & 2006 & $\begin{array}{l}\text { Consorcio encabezado por Suez (Francia) y grupo } \\
\text { Soldati (Argentina) }\end{array}$ \\
\hline Tandanor & 2007 & Proceso de quiebra \\
\hline Aerolíneas Argentinas y Austral & 2008 & Marsans (España) \\
\hline $\begin{array}{l}\text { Adm. de Fondos de Jubilaciones } \\
\text { y Pensiones }\end{array}$ & 2008 & Accionistas varios \\
\hline Fábrica Militar de Aviones & 2009 & Lockheed Martin (EE.UU.) \\
\hline YPF & 2012 & $\begin{array}{l}\text { Consorcio encabezado por Repsol (España) y Pe- } \\
\text { tersen (Argentina) }\end{array}$ \\
\hline Metrogas & 2012 & Consorcio encabezado por British Gas (Inglaterra) \\
\hline $\begin{array}{l}\text { Líneas ferroviarias Sarmiento y } \\
\text { Mitre }\end{array}$ & $2012-13$ & Grupo Plaza (grupo Cirigliano) \\
\hline Línea ferroviaria Belgrano Cargas & 2013 & Shima, Macri, Roggio, Emepa y sindicatos \\
\hline
\end{tabular}

Fuente: elaboración propia con información de medios periodísticos.

Un punto de inflexión en lo referido a la participación estatal en la economía fue la reestatización del sistema previsional, a mediados de 2008. La decisión oficial implicó el retorno del sistema de reparto y la posibilidad de desarmar ciertos dispositivos perversos que, sobre todo en la década de 1990, habían alentado la especulación financiera (Cenda, 2010). Asimismo, lo anterior derivó en que el Estado, a través de la Administración Nacional de la Seguridad Social (Anses), pasara a detentar participaciones accionarias y directores en algunas de las empresas más grandes del país que las AFJP habían acumulado a lo largo de los años, tales como Telecom Argentina, Siderar, Petrobras, Aluar, Importadora y Exportadora de La Patagonia, Transportadora de Gas del Sur, Pampa Energía, Mirgor, Transener, Solvay Indupa, Clarín y Edenor, entre otras.

\section{CONCLUSIONES}

El periodo de los gobiernos kirchneristas deja una serie de rupturas y continuidades con respecto al comportamiento de la cúpula empresaria y su grado de incidencia 
en la economía argentina. Una primera ruptura pasa por los renglones que relajan la restricción de dólares en la balanza de pagos: tras la salida de la convertibilidad se cerró la afluencia de dólares financieros. Los actores financieros beneficiados durante el régimen económico vigente entre 1976 y 2001 fueron remplazados centralmente por grandes actores, emplazados en plataformas exportadoras. El cambio de peso relativo de dichas fracciones se reflejó en la devaluación de 2002. En gran medida, a raíz de esa decisión de política económica, la cúpula empresaria en general, y su núcleo duro en particular, lograron aumentar su peso en la economía doméstica.

Así como los dólares financieros de otrora afluían de forma cíclica en función de las burbujas financieras internacionales, la dinámica de acumulación sustentada en los dólares comerciales presenta la debilidad de depender de la evolución de la demanda externa, así como del humor de los mercados sobre los commodities. Por esto, la economía argentina comenzó a presentar problemas cada vez más acuciantes desde comienzos del decenio de 2010.

En cuanto a las continuidades, la cúpula empresaria presenta un alto grado de extranjerización. Si bien este fenómeno se dio con mayor fuerza en la década de 1990, en el periodo kirchnerista también existieron compras por parte del capital extranjero a capitales nacionales. En este sentido, se pasó de una extranjerización extensiva a una intensiva: las ventas del capital foráneo superan el 50 \% de las ventas de la cúpula empresaria. De esta forma no se logró el objetivo de lograr la argentinización del empresariado, pese a que que el propio Estado nacional tendió a cubrir, más por necesidad que por planificación, aquellos espacios que debido a razones diversas quedaron vacantes por parte del capital privado.

El peso de la industria en las diversas tipologías del gran capital constituye a priori una ruptura con respecto a las etapas previas. Sin embargo, desde el punto de vista sectorial es un cambio en continuidad, ya que se está en presencia de industrias especializadas mayormente en ventajas comparativas con base en el procesamiento de recursos naturales. Es decir, la mayor significación fabril no se asoció con modificaciones en el perfil de especialización e inserción internacional predominante. En este sentido, dichas empresas fueron las más favorecidas en lo que respecta a la política de devaluación de 2002, el sostenimiento del tipo de cambio alto y factores externos que lo sostuvieron.

La única excepción a la regla del párrafo anterior lo constituye la actividad electrónica de ensamble de Tierra del Fuego: en ella, la participación de capitales nacionales es relevante. Se trata de actores que supieron aprovechar el dinamismo del mercado interno al amparo de la protección del Estado nacional. 
Respecto de este punto, en la etapa kirchnerista se destaca el ascenso de una nueva burguesía nacional que construyó el eje de su acumulación en mercados no transables; ergo, como los mercados externos no logran penetrar, se constituyen como nichos de privilegios. En ningún caso se manifiesta el ascenso de campeones nacionales que logren disputar porciones crecientes del mercado mundial. Con respecto a la vieja burguesía nacional, los ganadores de esta etapa comparten la especialización basada en el procesamiento de recursos naturales.

Al promediar el periodo estudiado se evidencia una reversión parcial de la extranjerización de las ventas de la cúpula que se vincula con el mayor dinamismo de los nuevos y viejos capitales nacionales, lo mismo que con el retorno del Estado. De todas maneras, el capital extranjero sigue predominando en los sectores de mayor relevancia en Argentina. Esto implica la pérdida de decisión nacional, reflejada en las presiones que acarrea sobre la balanza de pagos, y también involucra diversos sesgos que atentan contra la diversificación y la complejización de la estructura productiva.

\section{BIBLIOGRAFÍA}

Azpiazu, D.; Basualdo, E. y Khavisse, M. (1986). El nuevo poder económico en la Argentina de los ochenta. Buenos Aires: Legasa.

Azpiazu, D.; Manzanelli, P. y Schorr, M. (2011). Concentración y extranjerización. La Argentina en la posconvertibilidad. Buenos Aires: Capital Intelectual.

Azpiazu, D. y Schorr, M. (2010). Hecho en Argentina. Industria y economía, 1976-2007. Buenos Aires: Siglo XXI Editores.

Cantamutto, F.; Schorr, M. y Wainer, A. (2016): El sector externo de la economía argentina durante los gobiernos del kirchnerismo (2003-2015). En: Realidad Económica, n. 304, Buenos Aires.

Cantamutto, F. y Wainer, A. (2013). Economía política de la convertibilidad. Disputa de intereses y cambio de régimen. Buenos Aires: Capital Intelectual.

Cassini, L. (2015). Reinversión de utilidades y concentración en la industria manufacturera argentina en la posconvertibilidad. En: Realidad Económica, n. 292, Buenos Aires.

Castellani, A. (2009). Estado, empresas y empresarios. La construcción de ámbitos privilegiados de acumulación entre 1966 y 1989. Buenos Aires: Prometeo.

Castells, M. y Schorr, M. (2015). Cuando el crecimiento no es desarrollo. Algunos hechos estilizados de la dinámica industrial en la posconvertibilidad. En: Cuadernos de Economía Crítica, n. ${ }^{\circ} 2$.

Cenda -Centro de Estudios para el Desarrollo Argentino- (2010). La anatomía del nuevo patrón de crecimiento y la encrucijada actual. La economía argentina en el periodo 2002-2010. Buenos Aires: Cara o Ceca. 
Damill, M. y Frenkel, R. (2015). La economía argentina bajo los Kirchner: una historia en dos lustros. En: Gervasoni, C. y Peruzzotti, E. (Eds.), ¿Década ganada? Evaluando el legado del kirchnerismo. Buenos Aires: Debate.

Gaggero, A. y Schorr, M. (2016). La cúpula empresaria durante los gobiernos kirchneristas. Balance y legados. En: Realidad Económica, n. 297.

Gaggero, A. y Schorr, M. (2017). Las grandes empresas nacionales de la Argentina bajo los gobiernos del kirchnerismo. San Martín Idaes-Unsam, mimeografiado.

Gaggero, A.; Schorr, M. y Wainer, A. (2014). Restricción eterna. El poder económico durante el kirchnerismo. Buenos Aires: Futuro Anterior.

García Zanotti, G. (2016). El capital extranjero: uno de los orígenes de la debilidad estructural argentina. En: Realidad Económica, n. ${ }^{\circ} 299$.

González, M. y Manzanelli, P. (2012). La industria en la posconvertibilidad. El caso del complejo automotor. En: Área de Economía y Tecnología de la Flacso, Documento de Trabajo n. ${ }^{\circ} 25$.

Kulfas, M. (2016). Los tres kirchnerismos. Una historia de la economía argentina, 2003-2015. Buenos Aires: Siglo XXI Editores.

Lavarello, P. y Sarabia, M. (2015). La política industrial en la Argentina durante la década de 2000. Buenos Aires: Cepal, Serie Estudios y Perspectivas.

López, E. (2015). Los años post-neoliberales. De la crisis a la consolidación de un nuevo modo de desarrollo. Buenos Aires: Miño y Dávila.

Manzanelli, P. y Basualdo, E. (2016). Régimen de acumulación durante el ciclo de gobiernos kirchneristas. Un balance preliminar a través de las nuevas evidencias empíricas de las cuentas nacionales. En: Realidad Económica, n. ${ }^{\circ} 304$.

Mercatante, E. (2015). La economía argentina en su laberinto. Lo que dejan doce años de kirchnerismo. Buenos Aires: CEIP.

Moncaut, N. y Vázquez, D. (2017). El sendero de desarrollo chino y sus particularidades: incidencia e implicancias para los países sudamericanos. En: Realidad Económica, n. ${ }^{\circ} 305$.

Ortiz, R. y Schorr, M. (2006). La economía política del gobierno de Alfonsín: creciente subordinación al poder económico durante la década perdida. En: Pucciarelli, A. (Coord.), Los años de Alfonsín. ¿El poder de la democracia o la democracia del poder? Buenos Aires: Siglo XXI Editores.

Piva, A. (2015). Economía y política en la Argentina kirchnerista. Buenos Aires: Batalla de Ideas.

Porta, F.; Fernández Bugna, C. y Moldovan, P. (2009). Comercio e inserción internacional. En: Kosacoff, B. y Mercado, R. (Eds.), La Argentina ante la nueva internacionalización de la producción. Buenos Aires: Cepal - PNUD.

Porta, F.; Santarcángelo, J. y Schteingart, D. (2014): "Excedente y desarrollo industrial en Argentina: situación y desafíos", CEFID-AR, Documento de Trabajo n. 59, Buenos Aires.

Schorr, M. (2004). Industria y nación. Poder económico, neoliberalismo y alternativas de reindustrialización en la Argentina contemporánea. Buenos Aires: Edhasa. 
Schorr, M. (Coord.) (2013). Argentina en la posconvertibilidad: ¿desarrollo o crecimiento industrial? Estudios de economía política. Buenos Aires: Miño y Dávila.

Schorr, M.; Manzanelli, P. y Basualdo, E. (2012). Régimen económico y cúpula empresaria en la posconvertibilidad. En: Realidad Económica, n. 265.

Schorr, M. y Wainer, A. (2015). Algunos determinantes de la restricción externa en la Argentina. En: Márgenes. Revista de economía política, n. ${ }^{\circ} 1$.

Schorr, M. y Wainer, A. (2016). El comercio exterior de las grandes empresas de la Argentina en el siglo XXI. En: Ensayos de Economía, n. ${ }^{\circ}$ 49, Medellín.

Wainer, A. (2013). Cambios en el bloque en el poder a partir del abandono de la convertibilidad. ¿Una nueva hegemonía? En: Grigera, J. (Comp.), Argentina después de la convertibilidad. Buenos Aires: Imago Mundi. 